Research Article

\title{
Revised Rebound Hammer and Pull-Out Test Strength Curves for Fiber-Reinforced Concrete
}

\author{
Peng Deng $\mathbb{D}^{1},{ }^{1}$ Yan Sun, ${ }^{2}$ Yan Liu, ${ }^{1}$ and Xiaoxiao Song ${ }^{2}$ \\ ${ }^{1}$ Shandong Provincial Key Laboratory of Civil Engineering Disaster Prevention and Mitigation, \\ Shandong University of Science and Technology, Qingdao 266590, China \\ ${ }^{2}$ College of Civil Engineering and Architecture, Shandong University of Science and Technology, Qingdao 266590, China
}

Correspondence should be addressed to Peng Deng; dengpeng1226@sdust.edu.cn

Received 28 August 2019; Revised 23 January 2020; Accepted 24 January 2020; Published 24 February 2020

Academic Editor: Venu G. M. Annamdas

Copyright (C) 2020 Peng Deng et al. This is an open access article distributed under the Creative Commons Attribution License, which permits unrestricted use, distribution, and reproduction in any medium, provided the original work is properly cited.

Rebound hammer tests and postinstalled pull-out tests are commonly used for evaluating the compressive strength of ordinary concrete, and the strength of concrete is estimated by strength curves. However, using these strength curves to predict the compressive strength of carbon fiber-reinforced concrete (CFRC), polypropylene fiber-reinforced concrete (PFRC), and carbonpolypropylene hybrid fiber-reinforced concrete (HFRC) may lead to considerable uncertainties. Therefore, this study revises the strength curves derived from rebound hammer tests and postinstalled pull-out tests for ordinary concrete. 480 specimens of fiberreinforced concrete (FRC) of six strength grades are examined. Standard cube compressive strength tests are used as a reference, and the results of various regression models are compared. The linear model is determined as the most accurate model for postinstalled pull-out tests, whereas the power model is the most accurate for rebound hammer tests. The proposed strength curves have important applications for FRC engineering of the postinstalled pull-out tests and rebound hammer tests.

\section{Introduction}

Estimation of the in situ mechanical properties of existing concrete structures is imperative for evaluating their structural quality throughout their service lives. Among the currently available testing methods, rebound hammer tests, the core-drilling method, and postinstalled pull-out tests are the most widely used for assessing the compressive strength of concrete [1,2]. Compared with the core-drilling method [3], using the rebound hammer test and the postinstalled pull-out test to estimate the in-place strength of concrete allows larger amounts of data to be collected without a significant impact on the structure, resulting in higher reliability. However, the surface hardness and pull-out force of fiber-reinforced concrete (FRC) differ significantly from those of ordinary concrete $[4,5]$; therefore, evaluation of the compressive strength of FRC using the strength curves of ordinary concrete will lead to several uncertainties.

The rebound hammer method is a well-developed method for evaluating the compressive strength of on-site concrete [6]; however, its evaluation results can be affected by several factors. For example, its rebound number $(\mathrm{RN})$ is affected by concrete-containing crumb rubber (rubbercrete) [7] and surface properties of hardened concrete such as carbonation [8,9], age [10], service conditions [11], and water-cement ratio $(\mathrm{w} / \mathrm{cm})$ [12]. Moreover, compared with ordinary concrete, the $\mathrm{RN}$ of basalt fiber-reinforced recycled concrete is relatively low and exhibits a unique strength curve [13]. According to Ye et al. [5], the RN increases with increasing steel fiber content when the steel fiber content is $0.2-1.4 \%$ but decreases with increasing steel fiber content when the steel fiber content is $1.4-2.0 \%$. Mahapatra and Barai [14] found that specimens with hybrid fibers have greater RNs than specimens of ordinary concrete. Therefore, the incorporation of fibers into concrete can also affect the $\mathrm{RN}$.

Many practical factors affect the concrete strength measured via postinstalled pull-out tests, for example, the deformation of fibers such as inclined straight steel fibers [15], inclined hooked steel fibers [16], four other types of steel fibers [17], and the spacing of the steel mesh [18]. Lin and Ostertag [19] found that pull-out forces are influenced 
by the synergistic effect of micro/macrofibers, whereby PVA microfibers can effectively increase the pull-out force of the steel fibers. Roy et al. [20] concluded that the pull-out force and average bond stress increase with an increasing fiber volume fraction. Their experimental data also suggest that ultrahigh-performance concretes with fibers oriented perpendicular to the load direction increase the highest pull-out force, whereas ultrahigh-performance concretes with fibers oriented parallel to the load direction exhibit the lowest pullout load. According to Yoo and Shin [21], the pull-out force is marginally affected by the steel fiber content. However, none of these previous investigations on the compressive strength of FRC based on postinstalled pull-out tests has fully evaluated the relationship between compressive strength and the pull-out force of FRC.

The prediction models for the compressive strength of ordinary concrete established by JGJ/T 23-2011 [6] and CECS 69: 2011 [22] through rebound hammer tests and postinstalled pull-out tests have shown good prediction accuracy; however, the models do not provide significantly better predictions for FRC. In this study, a series of experimental investigations are conducted to estimate the suitability of using postinstalled pull-out tests and rebound hammer tests to predict the compressive strength of carbon fiber-reinforced concrete (CFRC), polypropylene fiberreinforced concrete (PFRC), and carbon-polypropylene hybrid fiber-reinforced concrete (HFRC). The pull-out force, $\mathrm{RN}$, and cubic compressive strength values are obtained from the experiments. Subsequently, the strength curves are analyzed and calibrated. The procedures used to develop the proposed model serve as a general guideline for developing strength curves in order to predict the compressive strength of concrete.

\section{Materials and Methods}

2.1. Materials. Ordinary Portland cement (OPA) with a strength class of $42.5 \mathrm{MPa}$ was used for all mixtures. Class I fly ash (FA) and water (tap water from the Laboratory of Shandong University of Science and Technology) were incorporated into the OPA. The FRC mixture design was based on previous studies $[23,24] .0 .9 \mathrm{~kg} / \mathrm{m}^{3}$ of polypropylene fibers and $0.2 \%$ (by volume) carbon fibers were added to obtain PFRC and CRFC, respectively (Figure 1). Conversely, the HFRC mixture comprised $0.9 \mathrm{~kg} / \mathrm{m}^{3}+0.2 \%$ by volume of polypropylene fibers and carbon fibers, respectively. Polynaphthalene sulfonate superplasticizer, hydroxypropyl methylcellulose, and antifoamer for concrete were employed to secure a suitable initial slump and air content values. Continuously graded crushed limestone aggregate with a nominal diameter of 5-32 $\mathrm{mm}$ was used, along with wellgraded river sand with a fineness modulus between 2.3 and 3.0 .

2.2. Mixing Design and Procedure. Cement, sand, stone, and fly ash were combined with polynaphthalene sulfonate superplasticizer. Polypropylene fibers and water were also incorporated. A $200 \mathrm{~L}$ pan mixer was used to mix all specimens. The ingredients were dry mixed at a low speed for $2 \mathrm{~min}$, and then water and polypropylene fibers were slowly added to the mixture. During casting, the specimens were vibrated for a few minutes until the frequency of surfacing air bubbles decreased significantly. Then, the specimens were demoulded $24 \mathrm{~h}$ after casting and full vibration and kept covered with waterproof films. PFRC specimens were cured for 28 days in a curing chamber with $95 \%$ relative humidity and ambient temperature $\left(20 \pm 2^{\circ} \mathrm{C}\right)$. The mixing procedure was similar for CFRC and HFRC. The material properties of fibers used in the manufacture of the FRC are shown in Table 1. Table 2 presents the mixing proportions for six different grades of concrete used in this study, namely, concrete of each strength grade, including CFRC, PFRC, and HFRC.

2.3. Experimental Design. 468 specimens were prepared to conduct the following overall experimental program, of which 360 and 108 were used for rebound hammer tests and postinstalled pull-out tests, respectively. The rebound hammer tests were conducted on cubic specimens measuring $150 \times 150 \times 150 \mathrm{~mm}$ (length $\times$ width $\times$ thickness) in accordance with JGJ/T 23-2011 [6]. Six different grades of concrete (C25, C30, C35, C40, C45, and C50) were used $\left(C_{x}\right.$ represents the cubic compressive strength grade, where $\mathrm{C}$ is simply an abbreviation of "concrete"). For postinstalled pull-out tests, cubic specimens measuring $200 \times 200 \times 200 \mathrm{~mm}$ (length $\times$ width $\times$ thickness) were used. After the tests, the compressive strength of $150 \mathrm{~mm} \mathrm{di-}$ mension specimens was obtained by the destructive standard cube compressive strength test method proposed by GB/T 50081-2002 [25]. The accuracy of rebound hammer tests and postinstalled pull-out tests was verified using the results of the compressive strength test. Subsequently, a carbonation test was conducted using the $150 \mathrm{~mm}$ dimension concrete specimens. The specimens were divided into six groups according to their cubic compressive strength (Table 3).

\subsection{Test Methods}

2.4.1. Standard Cube Compressive Strength Test. Standard cube compressive strength tests were conducted using a testing machine with different loading rates as a reference test. For specimens with a strength grade of C25, the loading rate was between $0.3 \mathrm{MPa} / \mathrm{s}$ and $0.5 \mathrm{MPa} / \mathrm{s}$. All other specimens had a loading rate of no more than $0.8 \mathrm{MPa} / \mathrm{s}$ [25]. The specimens were loaded until failure, and the maximum compressive strength was reported.

2.4.2. Rebound Hammer Test. The rebound hammer tests were conducted in accordance with JGJ/T 23-2011 [6]. The test specimens were fixed to limit their movement. Rebound hammer tests were performed on two faces (the two opposite faces in the noncasting direction) for each specimen. At least 10 readings were reported for each specimen, and their average was used to obtain the $\mathrm{RN}$ for each specimen. 


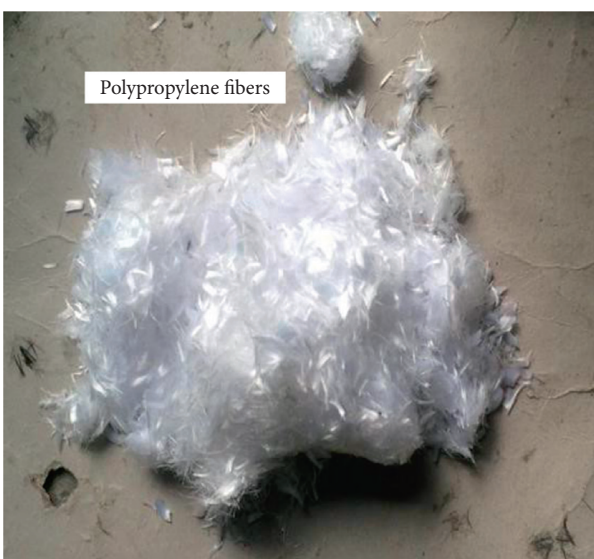

(a)

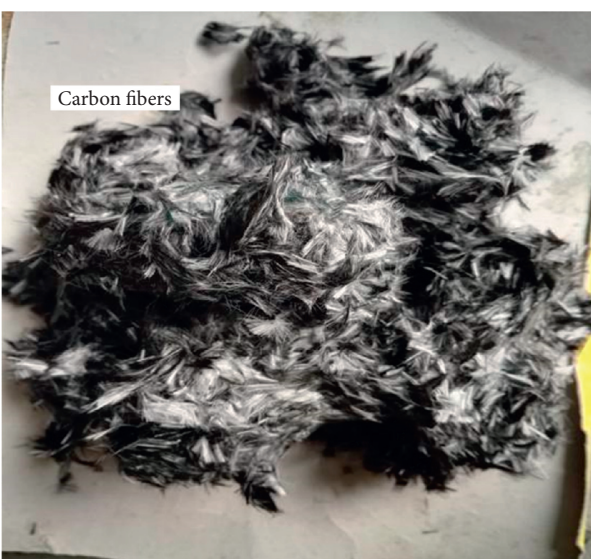

(b)

Figure 1: Fiber materials used in the fiber-reinforced concrete. (a) Polypropylene fibers. (b) Carbon fibers.

TABLE 1: Properties of fiber materials used in the concrete specimens.

\begin{tabular}{lcc}
\hline Fiber property & Polypropylene fiber & Carbon fiber \\
\hline Length $(\mathrm{mm})$ & 9 & 10 \\
Diameter $(\mathrm{mm})$ & 0.031 & 0.008 \\
Tensile strength $(\mathrm{MPa})$ & 300 & 3500 \\
Modulus of elasticity $(\mathrm{GPa})$ & 4 & 240 \\
\hline
\end{tabular}

TABLE 2: Mixing proportions of the different grades of concrete.

\begin{tabular}{lccccc}
\hline Group & Cement $\left(\mathrm{kg} / \mathrm{m}^{3}\right)$ & Sand $\left(\mathrm{kg} / \mathrm{m}^{3}\right)$ & Water $\left(\mathrm{kg} / \mathrm{m}^{3}\right)$ & Stone $\left(\mathrm{kg} / \mathrm{m}^{3}\right)$ & Superplasticizer $\left(\mathrm{kg} / \mathrm{m}^{3}\right)$ \\
\hline C25 & 314 & 728 & 174 & 1188 & 1203 \\
C30 & 357 & 677 & 174 & 1216 & 0.784 \\
C35 & 400 & 627 & 174 & 1228 & 0.891 \\
C40 & 443 & 578 & 174 & 1221 & 1.999 \\
C45 & 486 & 548 & 174 & 1213 & 1.214 \\
C50 & 529 & 520 & 174 & & 1.322 \\
\hline
\end{tabular}

TABLe 3: Experimental scheme showing the number of specimens tested for each type of test and concrete strength grade.

\begin{tabular}{lcccccccccccc}
\hline \multirow{2}{*}{ Group } & \multicolumn{1}{c}{ PFRC (number) } & \multicolumn{1}{c}{ CFRC (number) } & \multicolumn{4}{c}{ HFRC (number) } \\
& $P$ & $R$ & $S$ & $C$ & $P$ & $R$ & $S$ & $C$ & $P$ & $R$ & $S$ & $C$ \\
\hline C25 & 6 & 20 & 20 & 20 & 6 & 20 & 20 & 20 & 6 & 20 & 20 & 20 \\
C30 & 6 & 20 & 20 & 20 & 6 & 20 & 20 & 20 & 6 & 20 & 20 & 20 \\
C35 & 6 & 20 & 20 & 20 & 6 & 20 & 20 & 20 & 6 & 20 & 20 & 20 \\
C40 & 6 & 20 & 20 & 20 & 6 & 20 & 20 & 20 & 6 & 20 & 20 & 20 \\
C45 & 6 & 20 & 20 & 20 & 6 & 20 & 20 & 20 & 6 & 20 & 20 & 20 \\
C50 & 6 & 20 & 20 & 20 & 6 & 20 & 20 & 20 & 6 & 20 & 20 & 20 \\
\hline
\end{tabular}

$P=$ postinstalled pull-out test; $R=$ rebound hammer test; $S=$ standard cube compressive strength test; $C=$ carbonation test.

2.4.3. Postinstalled Pull-Out Test. The postinstalled pull-out tests were conducted as proposed by CECS 69: 2011 [22]. The pull-out specimens were cured for $28 \mathrm{~d}$, and then pull-out tests were performed using a multifunctional strength detector. Three test points were selected for each specimen group. At the selected test point, a circular hole was drilled with a diameter of $25 \mathrm{~mm}$ and a depth of $65 \mathrm{~mm}$. The testing point arrangement is shown in Figure 2(b). After the circular hole was cleaned, the anchor was slowly inserted into the circular hole and fixed to the fixture. A testing machine with a $0.5 \mathrm{kN} / \mathrm{s}$ loading rate was used to conduct the pull-out test. The ultimate pull-out force was determined by increasing the pull-out force to the FRC specimens until conical damage appeared. At least three readings were recorded from each specimen, and their average was used to obtain the pull-out force for each specimen.

2.4.4. Concrete Carbonation Test. After the specimens were destroyed by the standard cube compressive strength test, a circular hole was drilled with a diameter of $15 \mathrm{~mm}$ on two surfaces (the two opposite faces of the noncasting direction) of all specimens. The powder on the surface was cleaned, and $2 \%$ phenolphthalein alcohol solution was dropped on the edge of the circular hole. The carbonation depth was measured at predetermined measuring points, and at least three readings were recorded for each specimen; their average was used to determine the carbonation depth of concrete. 


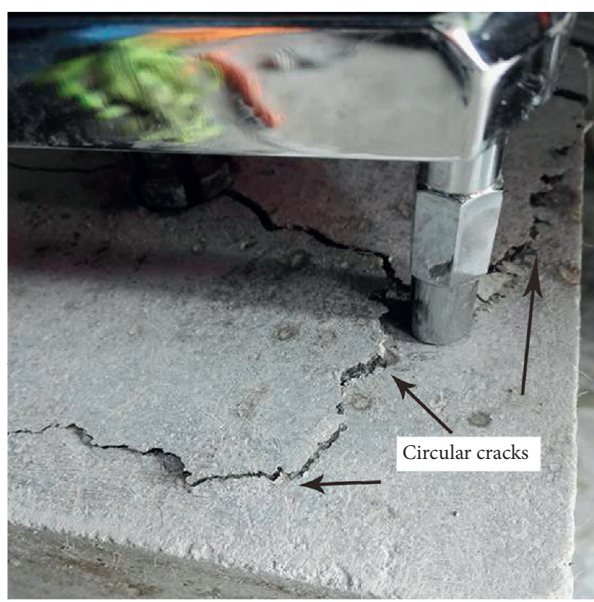

(a)

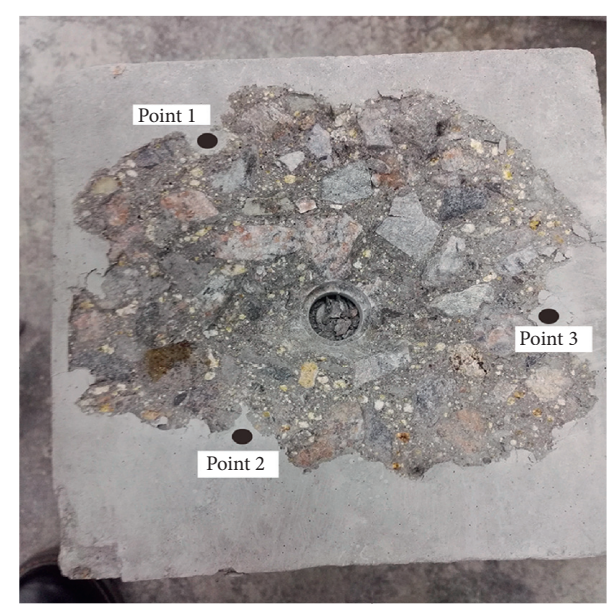

(b)

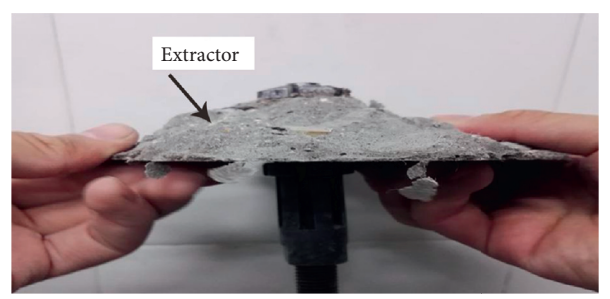

(c)

Figure 2: Photographs of the damaged specimen after postinstalled pull-out tests. (a) Circular crack on the surface of the PFRC. (b) Test specimen after the pull-out test. (c) The extractor.

2.5. Experimental Phenomena. After the postinstalled pullout test, there was no significant difference between the failure types of the three types of FRC; therefore, the failure type of PFRC specimens was used as an example for further analysis. As the pull-out force was increased, circular cracks appeared on the surface of the PFRC (Figure 2(a)). When the undamaged PFRC could no longer be loaded in this direction, the pull-out force reached its limit and led to rapid cracking and damage of the PFRC. The intact conical PFRC was then completely extracted (Figures 2(b) and 2(c)). After the concrete carbonation test, the carbonized concrete area was not discolored, but the uncarbonized area turned pink. Thus, the approximate carbonation depth was determined as the boundary between the carbonated and noncarbonated regions in Figure 3.

\section{Results and Discussion}

3.1. Results. Values of RN, the corresponding compressive strength, and the carbonation depth are reported in Table 4. Note that only some rebound hammer test results are presented due to the large amount of rebound data. $\mathrm{RN}$ increases with increasing cubic compressive strength for PFRC, CFRC, and HFRC. The pull-out force and corresponding cubic compressive strength are summarized in Table 5. Again, the pull-out force increases with increasing cubic compressive strength for all FRC specimens. HFRC generally exhibits the highest pull-out force, whereas PFRC exhibits the lowest values.

\subsection{Statistical Analysis}

3.2.1. Rebound Hammer Test Model. The five most widely used regression models for predicting the compressive strength of ordinary concrete as a function of RN are the JGJ/T 23-2011 (equation (1)) [6], linear (equation (2) [26], exponential (equation (3)) [27], second-order polynomial (equation (4)) [26], and power models (equation (5)) [26]. Among them, the carbonation depth is considered in equation (1), which has wide applicability. These models are, respectively, expressed as

$$
\begin{aligned}
& f_{c u}^{c}=A R_{\mathrm{m}}^{B} 10^{C d_{\mathrm{m}},} \\
& f_{c u}^{c}=A R_{\mathrm{m}}+B, \\
& f_{c u}^{c}=A e^{\left(B R_{\mathrm{m}}\right)}, \\
& f_{c u}^{c}=A R_{\mathrm{m}}^{2}+B R_{\mathrm{m}}+C, \\
& f_{c u}^{c}=A R_{\mathrm{m}}^{B},
\end{aligned}
$$

where $f_{c u}^{c}$ is the compressive strength, $R_{\mathrm{m}}$ is the recorded $\mathrm{RN} ; A, B$, and $C$ are the unknown parameters; and $d_{\mathrm{m}}$ is the depth of carbonation. However, ordinary concrete and FRC have different mechanical properties [28]; thus, the reliability of the models was validated using the experimental data for FRC. These models were fitted to the data, and their 


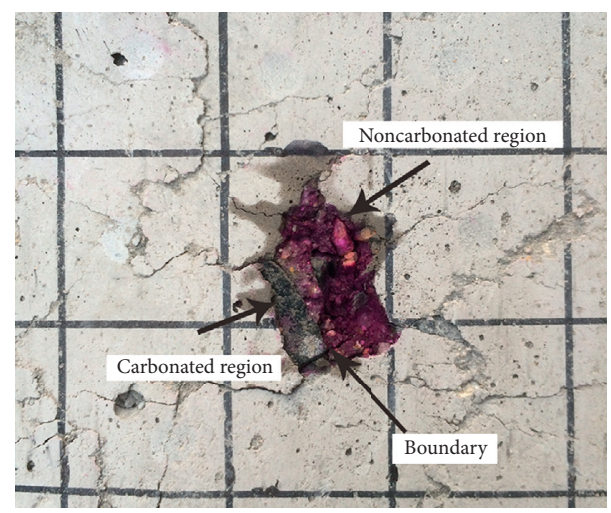

FIGURE 3: Fracture surface with sprayed phenolphthalein alcohol solution, which distinguishes between carbonated and noncarbonated regions.

TABle 4: Part of the RN and carbonation depths.

\begin{tabular}{|c|c|c|c|c|c|c|c|c|c|}
\hline \multirow{2}{*}{$\begin{array}{l}\text { Strength } \\
\text { grade }\end{array}$} & \multicolumn{3}{|c|}{ PFRC } & \multicolumn{3}{|c|}{ CFRC } & \multicolumn{3}{|c|}{ HFRC } \\
\hline & $\begin{array}{l}\text { Carbonation depth } \\
(\mathrm{mm})\end{array}$ & $\mathrm{RN}$ & $\begin{array}{c}\mathrm{CS} \\
(\mathrm{MPa})\end{array}$ & $\begin{array}{l}\text { Carbonation depth } \\
(\mathrm{mm})\end{array}$ & $\mathrm{RN}$ & $\begin{array}{c}\mathrm{CS} \\
(\mathrm{MPa})\end{array}$ & $\begin{array}{l}\text { Carbonation depth } \\
(\mathrm{mm})\end{array}$ & $\mathrm{RN}$ & $\begin{array}{c}\mathrm{CS} \\
(\mathrm{MPa})\end{array}$ \\
\hline \multirow{2}{*}{$\mathrm{C} 25$} & 1.5 & 30.9 & 29.0 & 1.0 & 29.2 & 29.8 & 1.0 & 30.5 & 28.2 \\
\hline & 0.5 & 30.9 & 30.2 & 1.0 & 29.5 & 30.7 & 1.0 & 31.4 & 30.9 \\
\hline \multirow{2}{*}{$\mathrm{C} 30$} & 1.0 & 33.4 & 33.1 & 2.5 & 34.3 & 35.2 & 1.0 & 35.2 & 36.5 \\
\hline & 0.5 & 33.6 & 34.4 & 1.5 & 34.8 & 33.2 & 1.0 & 35.7 & 36.4 \\
\hline \multirow{2}{*}{ C35 } & 1.5 & 36.4 & 39.1 & 1.0 & 36.3 & 40.1 & 1.5 & 37.6 & 41.7 \\
\hline & 1.0 & 36.6 & 37.8 & 0.5 & 36.6 & 43.2 & 2.0 & 37.7 & 40.6 \\
\hline \multirow{2}{*}{$\mathrm{C} 40$} & 1.5 & 38.5 & 44.3 & 1.0 & 40.9 & 44.1 & 1.0 & 40.1 & 46.3 \\
\hline & 0.5 & 38.5 & 44.7 & 0.5 & 41.3 & 44.2 & 1.5 & 40.4 & 46.3 \\
\hline \multirow{2}{*}{ C45 } & 1.0 & 39.6 & 45.5 & 1.0 & 40.2 & 48.8 & 1.0 & 42.2 & 49.5 \\
\hline & 0.5 & 39.6 & 47.5 & 1.0 & 40.3 & 49.0 & 1.0 & 43.0 & 51.3 \\
\hline \multirow{2}{*}{ C50 } & 1.0 & 41.4 & 51.3 & 1.5 & 43.0 & 54.4 & 1.0 & 45.3 & 53.8 \\
\hline & 0.5 & 41.8 & 50.7 & 1.0 & 43.5 & 50.2 & 2.0 & 45.5 & 53.2 \\
\hline
\end{tabular}

$\mathrm{RN}=$ rebound number; $\mathrm{CS}=$ compressive strength.

mean relative error $(\delta)$, standard of variation $\left(e_{r}\right)$, and $R$ squared $\left(R^{2}\right)$ values were analyzed.

Regression curves derived from the five models (equations (1)-(5)) were used to predict the compressive strength of PFRC (Figure 4(a)). G0 represents equation (1) with a carbonation depth of $0 \mathrm{~mm}, \mathrm{G} 1$ represents equation (1) with a carbonation depth of $1 \mathrm{~mm}$, and G3 represents equation (1) with a carbonation depth of $3 \mathrm{~mm}$. The results of the $\mathrm{G} 1$, linear, exponential, second-order polynomial, and power models are approximately identical (i.e., they exhibit similar trends) for compressive strength. In the G0 model, the compressive strength of PFRC is approximately 19\% higher than in the G3 model; therefore, it is necessary to consider the influence of the carbonation depth on the compressive strength. Similar results for CFRC and HFRC are shown in Figures 4(b) and 4(c).

The derived mathematical equations and $R^{2}, e_{r}$, and $\delta$ values for the PFRC, CFRC, and HFRC models are recorded in Tables 6-8, respectively. The highest $R^{2}$ value $(0.8915)$ and lowest $\delta$ value $(5.5 \%)$ and $e_{r}$ value $(6.6 \%)$ are obtained for PFRC using the JGJ/T 23-2011 model. Thus, compressive strength can be most accurately predicted using the $\mathrm{RN}$ derived by the JGJ/T 23-2011 model. Using this criterion, the
$R^{2}$ values of PFRC, CFRC, and HFRC are $0.8915,0.8870$, and 0.8725 , respectively, which are all close to 1 . Moreover, $\delta, R^{2}$, and $e_{r}$ values for RN meet the requirements of the JGJ/T 232011 model. Overall, the proposed strength curves can predict the compressive strength with acceptable accuracy and be used to predict a wide range of new data.

3.2.2. Comparison between the Experimental Results for Different Concrete Specimens in the Rebound Hammer Test. Based on a literature review, it can be observed that most of the current literature is primarily regarding the strength curves of basalt FRC and ordinary concrete, and there are limited studies on the correlation between the $\mathrm{RN}$ and compressive strength measured in the rebound hammer tests of PFRC, CFRC, and HFRC. Various models can be used to estimate the compressive strength of concrete, which can also be obtained from previously measured data. Zhao and Ma [29] studied the cubic compressive strength of prepreg basalt FRC and established the corresponding strength curve using second-order polynomial regression. Based on the rebound hammer test, Ali-Benyahia et al. [1] studied the strength curve of ordinary concrete and revised 
TABLE 5: Summary of postinstalled pull-out test results.

\begin{tabular}{|c|c|c|c|c|c|c|c|c|c|}
\hline \multirow{2}{*}{ Grade } & \multicolumn{3}{|c|}{ PFRC } & \multicolumn{3}{|c|}{ CFRC } & \multicolumn{3}{|c|}{ HFRC } \\
\hline & Group & $\mathrm{PF}(\mathrm{kN})$ & $\mathrm{CS}(\mathrm{MPa})$ & Group & $\mathrm{PF}(\mathrm{kN})$ & $\mathrm{CS}(\mathrm{MPa})$ & Group & $\mathrm{PF}(\mathrm{kN})$ & $\mathrm{CS}(\mathrm{MPa})$ \\
\hline \multirow{6}{*}{$\mathrm{C} 25$} & PFRC25-1 & 15.58 & 29.61 & CFRC25-1 & 16.69 & 32.19 & HFRC25-1 & 16.74 & 31.40 \\
\hline & PFRC25-2 & 15.04 & 30.33 & CFRC25-2 & 16.49 & 30.48 & HFRC25-2 & 18.39 & 31.44 \\
\hline & PFRC25-3 & 14.32 & 29.89 & CFRC25-3 & 17.02 & 30.22 & HFRC25-3 & 17.05 & 31.44 \\
\hline & PFRC25-4 & 15.08 & 28.28 & CFRC25-4 & 16.07 & 32.96 & HFRC25-4 & 17.93 & 32.05 \\
\hline & PFRC25-5 & 16.02 & 29.04 & CFRC25-5 & 15.92 & 30.82 & HFRC25-5 & 16.89 & 33.27 \\
\hline & PFRC25-6 & 14.75 & 29.05 & CFRC25-6 & 17.52 & 31.39 & HFRC25-6 & 17.52 & 31.07 \\
\hline \multirow{6}{*}{ C30 } & PFRC30-1 & 15.48 & 33.71 & CFRC30-1 & 17.39 & 35.53 & HFRC30-1 & 19.01 & 35.27 \\
\hline & PFRC30-2 & 16.46 & 33.27 & CFRC30-2 & 19.86 & 34.33 & HFRC30-2 & 19.33 & 35.86 \\
\hline & PFRC30-3 & 16.23 & 34.21 & CFRC30-3 & 18.42 & 35.35 & HFRC30-3 & 19.86 & 35.27 \\
\hline & PFRC30-4 & 16.89 & 32.27 & CFRC30-4 & 18.97 & 36.47 & HFRC30-4 & 18.58 & 36.19 \\
\hline & PFRC30-5 & 17.60 & 33.18 & CFRC30-5 & 18.07 & 35.61 & HFRC30-5 & 20.62 & 36.14 \\
\hline & PFRC30-6 & 17.16 & 34.97 & CFRC30-6 & 18.76 & 34.92 & HFRC30-6 & 19.14 & 36.91 \\
\hline \multirow{6}{*}{ C35 } & PFRC35-1 & 18.67 & 37.22 & CFRC35-1 & 21.71 & 39.89 & HFRC35-1 & 22.37 & 39.80 \\
\hline & PFRC35-2 & 18.44 & 38.82 & CFRC35-2 & 20.84 & 39.98 & HFRC35-2 & 22.38 & 41.32 \\
\hline & PFRC35-3 & 19.76 & 38.37 & CFRC35-3 & 20.29 & 41.57 & HFRC35-3 & 20.40 & 40.32 \\
\hline & PFRC35-4 & 17.71 & 38.25 & CFRC35-4 & 20.79 & 41.00 & HFRC35-4 & 21.39 & 41.37 \\
\hline & PFRC35-5 & 18.53 & 39.43 & CFRC35-5 & 20.11 & 39.80 & HFRC35-5 & 20.87 & 39.71 \\
\hline & PFRC35-6 & 19.23 & 40.01 & CFRC35-6 & 21.04 & 41.00 & HFRC35-6 & 20.94 & 41.02 \\
\hline \multirow{6}{*}{$\mathrm{C} 40$} & PFRC40-1 & 19.74 & 44.04 & CFRC40-1 & 21.91 & 42.97 & HFRC40-1 & 24.00 & 44.68 \\
\hline & PFRC40-2 & 21.63 & 43.98 & CFRC40-2 & 22.16 & 44.43 & HFRC40-2 & 23.10 & 44.26 \\
\hline & PFRC40-3 & 21.68 & 42.30 & CFRC40-3 & 23.58 & 44.77 & HFRC40-3 & 22.58 & 44.68 \\
\hline & PFRC40-4 & 20.03 & 43.71 & CFRC40-4 & 22.78 & 45.28 & HFRC40-4 & 23.51 & 45.16 \\
\hline & PFRC40-5 & 20.69 & 43.73 & CFRC40-5 & 21.61 & 45.28 & HFRC40-5 & 23.90 & 45.98 \\
\hline & PFRC40-6 & 20.95 & 42.11 & CFRC40-6 & 22.98 & 44.74 & HFRC40-6 & 22.63 & 47.03 \\
\hline \multirow{6}{*}{$\mathrm{C} 45$} & PFRC45-1 & 21.78 & 47.92 & CFRC45-1 & 23.46 & 48.61 & HFRC45-1 & 25.76 & 48.07 \\
\hline & PFRC45-2 & 23.00 & 46.94 & CFRC45-2 & 24.51 & 48.53 & HFRC45-2 & 24.94 & 48.77 \\
\hline & PFRC45-3 & 22.62 & 47.92 & CFRC45-3 & 25.18 & 49.13 & HFRC45-3 & 25.50 & 49.38 \\
\hline & PFRC45-4 & 23.34 & 46.01 & CFRC45-4 & 25.66 & 47.07 & HFRC $45-4$ & 24.16 & 49.47 \\
\hline & PFRC45-5 & 21.25 & 46.94 & CFRC45-5 & 24.28 & 48.88 & HFRC45-5 & 25.12 & 49.12 \\
\hline & PFRC45-6 & 22.71 & 46.19 & CFRC45-6 & 24.66 & 49.47 & HFRC45-6 & 26.26 & 49.90 \\
\hline \multirow{6}{*}{ C50 } & PFRC50-1 & 23.31 & 50.04 & CFRC50-1 & 26.48 & 51.27 & HFRC50-1 & 27.21 & 52.51 \\
\hline & PFRC50-2 & 24.07 & 51.82 & CFRC50-2 & 25.51 & 53.21 & HFRC50-2 & 26.70 & 53.03 \\
\hline & PFRC50-3 & 23.74 & 51.07 & CFRC50-3 & 26.96 & 52.75 & HFRC50-3 & 27.84 & 53.30 \\
\hline & PFRC50-4 & 24.85 & 51.27 & CFRC50-4 & 26.33 & 53.40 & HFRC50-4 & 28.24 & 53.47 \\
\hline & PFRC50-5 & 24.15 & 50.11 & CFRC50-5 & 26.70 & 53.34 & HFRC50-5 & 27.16 & 52.95 \\
\hline & PFRC50-6 & 22.98 & 51.78 & CFRC50-6 & 26.53 & 52.38 & HFRC50-6 & 26.95 & 54.51 \\
\hline
\end{tabular}

$\mathrm{PF}=$ Pull-out force; $\mathrm{CS}=$ compressive strength.

the relationship between the $\mathrm{RN}$ and compressive strength. Atoyebi et al. [30] employed the rebound hammer test to assess the compressive strength of concrete using the rebound index, and the relationship between the compressive strength and $\mathrm{RN}$ was determined using linear regression. The results of the comparisons of the different models are summarized in Table 9.

Comparisons of the regression curves obtained from the rebound hammer test, shown in Table 9, demonstrate that the strength curves of PFRC, CFRC, and HFRC are significantly different from those of basalt FRC. This phenomenon is due to the large difference in material properties between basalt fibers, polypropylene fibers, and carbon fibers. There are differences among the results obtained using the models of Ali-Benyahia et al. [1] and Atoyebi et al. [30] in the strength curves and the $R^{2}$ value of ordinary concrete, which may be because the test conditions for the ordinary concrete (i.e., the setup and method employed for the rebound hammer test), experimental test conditions, and construction conditions are different for these models. All models with basalt FRC and ordinary concrete exhibit relatively strong correlations, which are further improved $\left(R^{2}>0.87\right)$ for the PFRC, CFRC, and HFRC models. Currently, no universal method or standard can be followed for on-site strength measurements of PFRC, CFRC, and HFRC. In summary, the rebound hammer test enjoys wide applicability for the strength measurement of PFRC, CFRC, and HFRC and will bring appreciable social and economic benefits.

3.2.3. Postinstalled Pull-Out Test Model. The analysis employed a linear regression to establish the relationship between compressive strength and pull-out force. The regression model is expressed as follows:

$$
E(y)=\alpha+\beta x,
$$




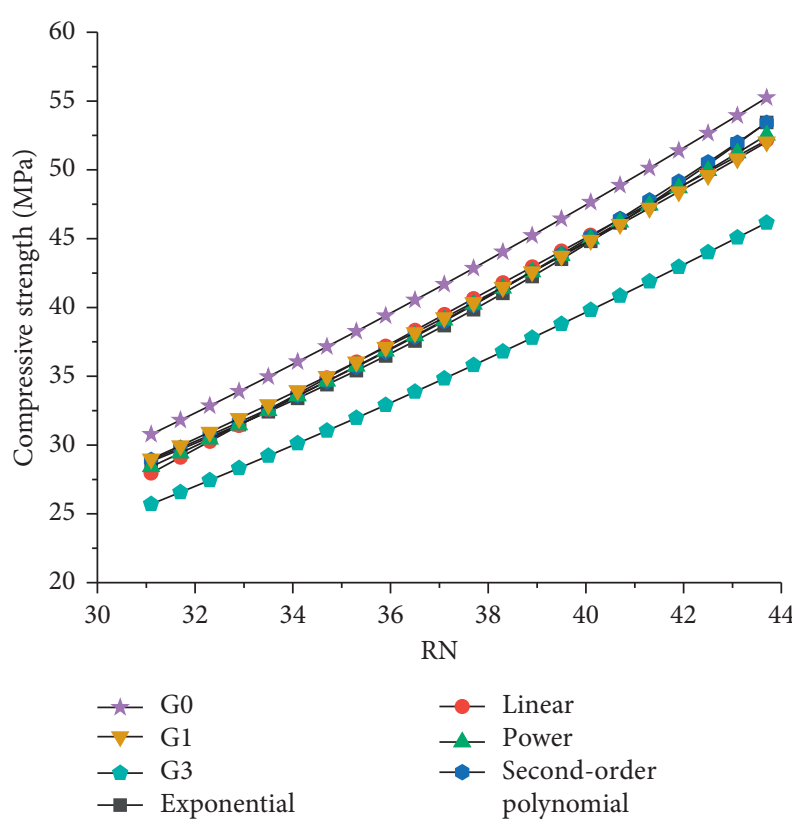

(a)

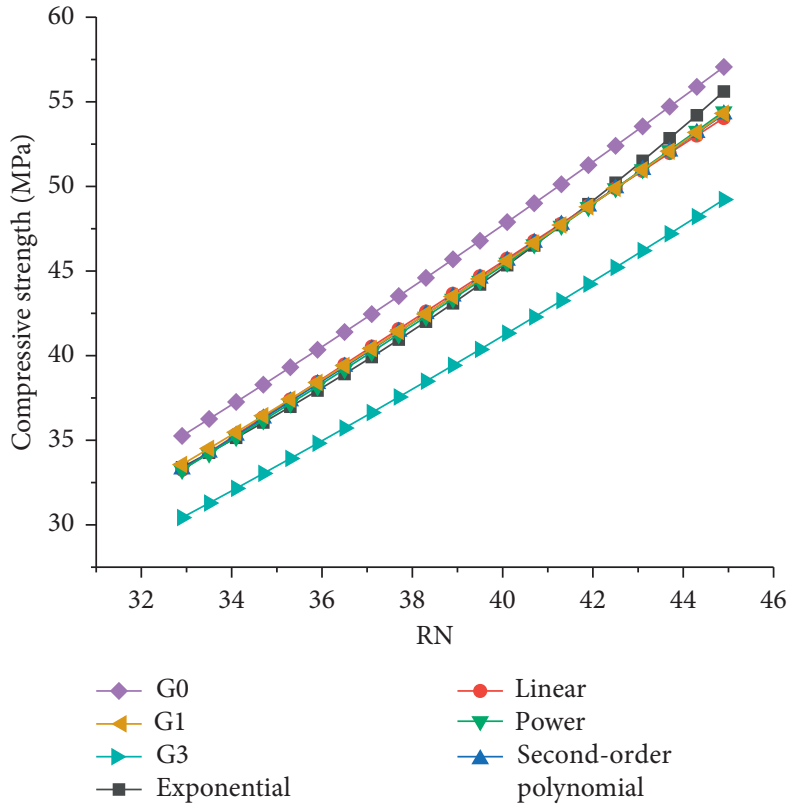

(b)

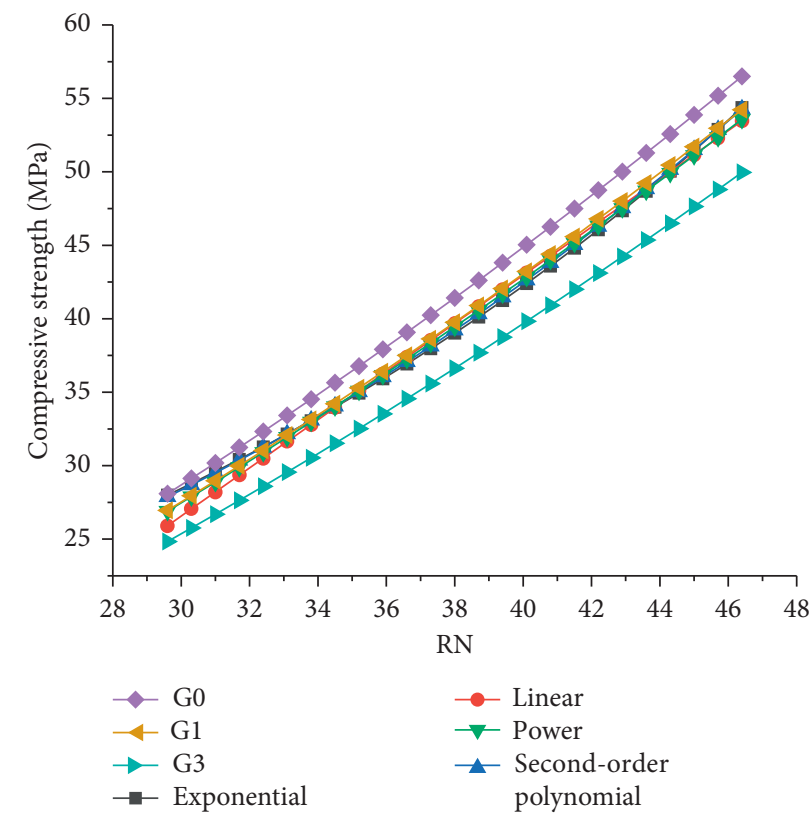

(c)

Figure 4: Regression curves of (a) PFRC, (b) CFRC, and (c) HFRC predicted using the G0, G1, G3, exponential, linear, second-order polynomial, and power models.

TABLE 6: Model equations used to estimate the relationship between PFRC compressive strength and RN.

\begin{tabular}{|c|c|c|c|c|}
\hline Regression models & Equations & $\delta(\%)$ & $e_{r}(\%)$ & $R^{2}$ \\
\hline JGJ/T 23-2011 & $f_{c u}^{c}=0.08324 R_{\mathrm{m}}^{1.72021} 10^{-0.02602 d_{\mathrm{m}}}$ & 5.5 & 6.6 & 0.8915 \\
\hline Linear & $f_{c u}^{c}=1.9202 R_{\mathrm{m}}-31.756$ & 6.3 & 7.5 & 0.8560 \\
\hline Exponential & $f_{c u}^{c}=6.2799 e^{\left(0.049 R_{\mathrm{m}}\right)}$ & 6.7 & 8.1 & 0.8481 \\
\hline Second-order polynomial & $f_{c u}^{c}=0.0398 R_{\mathrm{m}}^{2}-1.0328 R_{\mathrm{m}}+22.548$ & 6.3 & 7.5 & 0.8602 \\
\hline Power & $f_{c u}^{c}=0.0573 R_{\mathrm{m}}^{1.8057}$ & 6.4 & 7.6 & 0.8532 \\
\hline
\end{tabular}


TABLE 7: Model equations used to estimate the relationship between CFRC compressive strength and RN.

\begin{tabular}{|c|c|c|c|c|}
\hline Regression models & Equations & $\delta(\%)$ & $e_{r}(\%)$ & $R^{2}$ \\
\hline JGJ/T 23-2011 & $f_{c u}^{c}=0.15396 R_{\mathrm{m}}^{1.55588} 10^{-0.02147 d_{\mathrm{m}}}$ & 5.3 & 6.3 & 0.8870 \\
\hline Linear & $f_{c u}^{c}=1.7471 R_{\mathrm{m}}-24.185$ & 6.1 & 7.4 & 0.8543 \\
\hline Exponential & $f_{c u}^{c}=8.2084 e^{\left(0.0427 R_{\mathrm{m}}\right)}$ & 6.1 & 7.3 & 0.8507 \\
\hline Second-order polynomial & $f_{c u}^{c}=0.0075 R_{\mathrm{m}}^{2}-1.1794 R_{\mathrm{m}}-13.603$ & 6.1 & 7.3 & 0.8546 \\
\hline Power & $f_{c u}^{c}=0.1275 R_{\mathrm{m}}^{1.593}$ & 6.1 & 7.2 & 0.8514 \\
\hline
\end{tabular}

TABLE 8: Model equations used to estimate the relationship between HFRC compressive strength and RN.

\begin{tabular}{|c|c|c|c|c|}
\hline Regression models & Equations & $\delta(\%)$ & $e_{r}(\%)$ & $R^{2}$ \\
\hline JGJ/T 23-2011 & $f_{c u}^{c}=0.14494 R_{\mathrm{m}}^{1.55466} 10^{-0.0178 d_{\mathrm{m}}}$ & 5.8 & 6.8 & 0.8725 \\
\hline Linear & $f_{c u}^{c}=1.6399 R_{\mathrm{m}}-22.631$ & 6.2 & 7.3 & 0.8564 \\
\hline Exponential & $f_{c u}^{c}=8.6977 e^{\left(0.0395 R_{\mathrm{m}}\right)}$ & 5.9 & 6.9 & 0.8581 \\
\hline Second-order polynomial & $f_{c u}^{c}=0.0263 R_{\mathrm{m}}^{2}-0.428 R_{\mathrm{m}}-17.505$ & 5.9 & 7.0 & 0.8611 \\
\hline Power & $f_{c u}^{c}=0.1497 R_{\mathrm{m}}^{1.5324}$ & 6.0 & 7.1 & 0.8533 \\
\hline
\end{tabular}

TABLE 9: Models for estimation of in-place concrete compressive strength.

\begin{tabular}{lccc}
\hline Estimation model name & Materials & Equations & $R^{2}$ \\
\hline Zhao and Ma model [29] & Basalt FRC & $f_{c u}^{c}=0.07 R_{\mathrm{m}}^{2}-3.39 R_{\mathrm{m}}+74.05$ & 0.5300 \\
Ali-Benyahia et al. model [1] & Ordinary concrete & $f_{c u}^{c}=0.9874 R_{\mathrm{m}}-15.034$ & 0.7800 \\
Atoyebi et al. model [30] & Ordinary concrete & $f_{c u}^{c}=0.1086 R_{\mathrm{m}}+25.653$ & 0.8680 \\
& PFRC & $f_{c u}^{c}=0.08324 R_{\mathrm{m}}^{1.7021} 10^{-0.02602 d_{\mathrm{m}}}$ & 0.8915 \\
\multirow{2}{*}{ The models in this paper } & CFRC & $f_{c u}^{c}=0.15396 R_{\mathrm{m}}^{1.55588} 10^{-0.02147 d_{\mathrm{m}}}$ & 0.8870 \\
& HFRC & $f_{c u}^{c}=0.14494 R_{\mathrm{m}}^{1.55466} 10^{-0.0178 d_{\mathrm{m}}}$ & 0.8725 \\
\hline
\end{tabular}

where $E(y)$ is the expected value of $y$ as a random variable, $\alpha$ and $\beta$ are the unknown parameters, and $x$ is the independent variable. The values of $y, \alpha$, and $\beta$ values were obtained from the experimental data. The empirical regression model was then obtained (equation (7)), in which $a$ and $b$ were obtained by the least-squares method:

$$
\widehat{y}=a+b x
$$

where $\hat{y}$ is the value of $E(y)$ and $a$ and $b$ are the values of $\alpha$ and $\beta$, respectively. Many regression models can be utilized to predict the relationship between pull-out force and compressive strength. The more widely used models for postinstalled pull-out tests on ordinary concrete are linear (equation (8)), exponential (equation (9)), and power (equation (10)) models [3]:

$$
\begin{aligned}
& f_{c u}^{c}=A F+B, \\
& f_{c u}^{c}=A e^{(B F)}, \\
& f_{c u}^{c}=A F^{B},
\end{aligned}
$$

where $f_{c u}^{c}$ is the unknown parameter, $F$ is the known parameter, and $A$ and $B$ are the regression parameters obtained by the least-squares method. In this study, the known parameters $(F)$ are the pull-out forces of FRC, and the unknown parameters $\left(f_{c u}^{c}\right)$ are the compressive strengths. However, ordinary concrete and FRC show different failure modes [31]. In this study, the reliability of the models was validated using the experimental data for FRC and by analyzing the standard deviation $\left(e_{r}\right)$, coefficient of variation $\left(C_{v}\right)$, correlation coefficient $(R)$, and mean relative error $(\delta)$.

The derived mathematical equations and $R, \delta, e_{r}$, and $C_{v}$ values for the PFRC models are recorded in Table 10. The highest $R$ value $(0.9688)$ and the lowest $\delta$ value $(4.06 \%)$ and $C_{v}$ value $(4.67 \%)$ for PFRC are obtained by the linear regression model. Thus, the linear regression model can more accurately predict the relationship between compressive strength and pull-out forces. Similar results obtained for CFRC and HFRC are shown in Tables 11 and 12, respectively. All $R$ values for modelled strength curves are close to 1 , and $\delta, e_{r}$, and $C_{v}$ requirements are met by the linear regression model, indicating that the predicted strength values are within the desired accuracy.

Strength curves derived using the linear regression model to predict the relationship between the pull-out forces and compressive strength of PFRC, CFRC, and HFRC are shown in Figure 5. The compressive strength clearly increases with increasing pull-out forces. At lower compressive strength, the pull-out forces are relatively similar for CFRC, PFRC, and HFRC, which is due to the lower bond stress between the fibers and the concrete. For the specimens with higher compressive strength, the pull-out forces of CFRC are larger than those of PFRC under the same 
TABLE 10: Various regression models used to estimate the compressive strength of PFRC from postinstalled pull-out forces.

\begin{tabular}{lcccc}
\hline Regression models & Equations & $R$ & $\delta(\%)$ & $e_{r}(\%)$ \\
\hline Linear & $f_{c u}^{c}=2.2535 F-3.821$ & 0.9688 & 4.06 & 4.85 \\
Exponential & $f_{c u}^{c}=12.907 e^{(0.0572 F)}$ & 0.9640 & 4.30 & 5.18 \\
Power & $f_{c u}^{c}=1.4947 F^{1.1067}$ & 0.9681 & 4.10 & 4.67 \\
\hline
\end{tabular}

TABLE 11: Various regression models used to estimate the compressive strength of CFRC from postinstalled pull-out forces.

\begin{tabular}{lcccc}
\hline Regression models & \multicolumn{1}{c}{ Equations } & $R$ & $\delta(\%)$ & $e_{r}(\%)$ \\
\hline Linear & $f_{c u}^{c}=2.1089 F-3.3377$ & 0.9739 & 3.18 & 4.25 \\
Exponential & $f_{c u}^{c}=13.761 e^{(0.0512 F)}$ & 0.9698 & 3.45 & 4.04 \\
Power & $f_{c u}^{c}=1.059 F^{1.0835}$ & 0.9721 & 3.19 & 4.30 \\
\hline
\end{tabular}

TABLE 12: Various regression models used to estimate the compressive strength of HFRC from postinstalled pull-out forces.

\begin{tabular}{lcccc}
\hline Regression models & Equations & $R$ & $\delta(\%)$ & $e_{r}(\%)$ \\
\hline Linear & $f_{c u}^{c}=2.1189 F-4.7076$ & 0.9768 & 3.07 & 3.99 \\
Exponential & $f_{c u}^{c}=13.526 e^{(0.0507 F)}$ & 0.9723 & 3.47 & 4.25 \\
Power & $f_{c u}^{c}=1.318 F^{1.1184}$ & 0.9754 & 3.10 & 4.79 \\
\hline
\end{tabular}

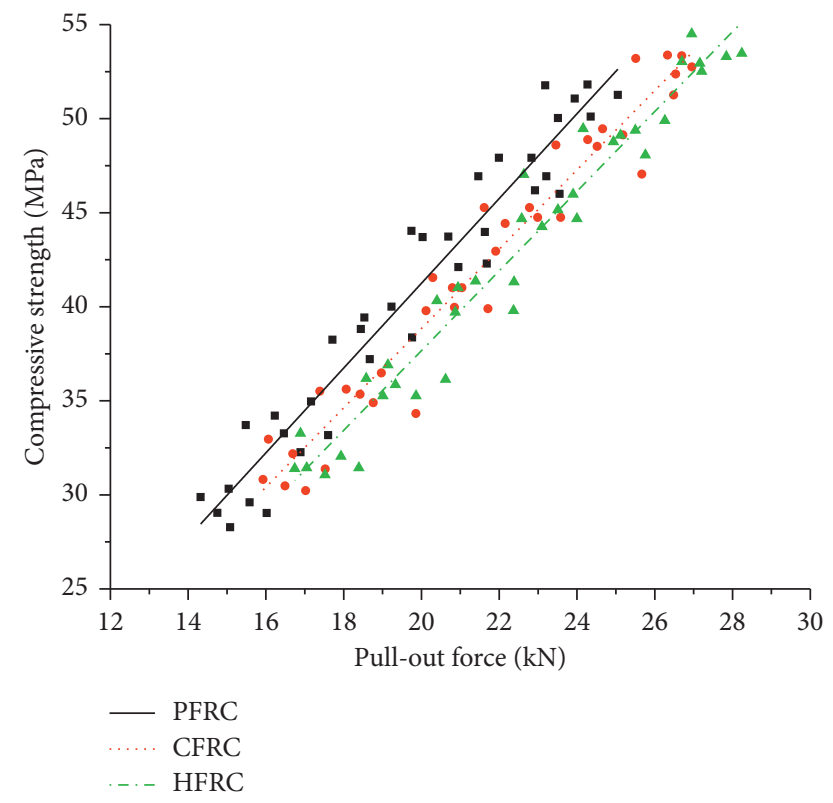

FIgURE 5: Relationship between pull-out force and compressive strength for three types of FRC.

compressive strength. This is because carbon fibers with a higher modulus of elasticity and tensile strength lead to significant improvement in the cracking performance of CFRC. HFRC exhibits the lowest compressive strength when compared to CFRC and PFRC.

3.2.4. Comparison between the Experimental Results $\mathrm{Ob}$ tained for Different Specimens in the Postinstalled Pull-Out Test. Based on a literature review, it can be seen that most studies are concerning the strength curves of basalt FRC and ordinary concrete. However, in the postinstalled pull-out test of PFRC, CFRC, and HFRC, the correlation between the pull-out force and compressive strength is rarely studied. $\mathrm{Li}$
[32] obtained the strength curve of steel fiber-reinforced mortars through the postinstalled pull-out test. Li et al. [33] performed the postinstalled pull-out test to measure the compressive strength for ordinary concrete and obtained the corresponding strength curves. The correlation models presented in the current literature are studied in comparison with the models proposed in this paper. The correlation models are summarized in Table 13, and the correlation models presented in the current literature are shown in Figure 6.

Comparisons of the regression curves (Figures 5 and 6) obtained from the postinstalled pull-out test show that the strength curves of PFRC, CFRC, and HFRC are significantly different from those of steel fiber-reinforced mortar. This is 
TABLE 13: Models for estimating compressive strength of in-place concrete postinstalled pull-out test.

\begin{tabular}{|c|c|c|c|c|}
\hline Estimation model name & Materials & Equations & $e_{r}(\%)$ & $R$ \\
\hline Li model [32] & Steel fiber-reinforced mortar & $f_{c u}^{c}=1.8 F+9.1$ & 5.43 & 0.9260 \\
\hline \multirow{2}{*}{ Li et al. model [33] } & Ordinary concrete & $f_{c u}^{c}=1.5317 F^{0.9413}$ & 5.97 & 0.9560 \\
\hline & PFRC & $f_{c u}^{c}=2.2535 F-3.821$ & 4.85 & 0.9688 \\
\hline \multirow[t]{2}{*}{ The models in this paper } & CFRC & $f_{c u}^{c}=2.1089 F-3.3377$ & 4.25 & 0.9739 \\
\hline & HFRC & $f_{c u}^{c}=2.1189 F-4.7076$ & 3.99 & 0.9768 \\
\hline
\end{tabular}

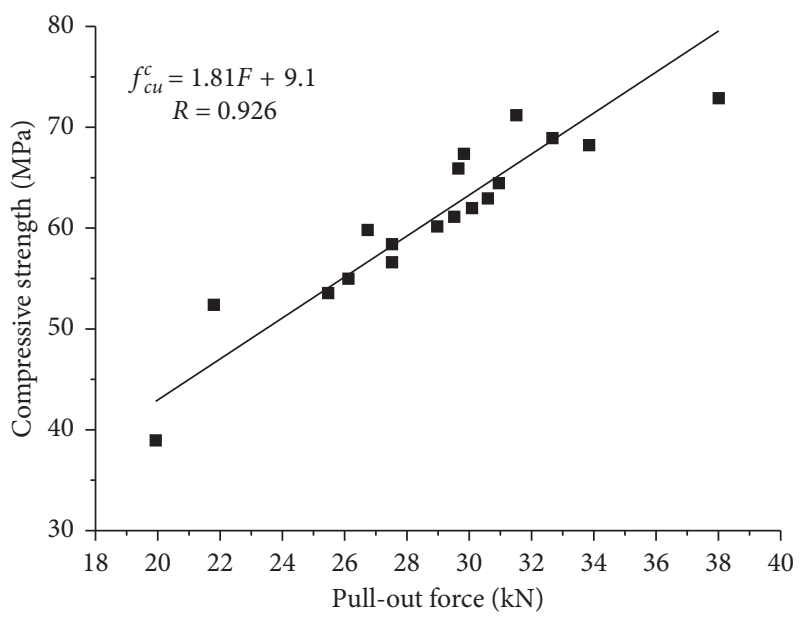

(a)

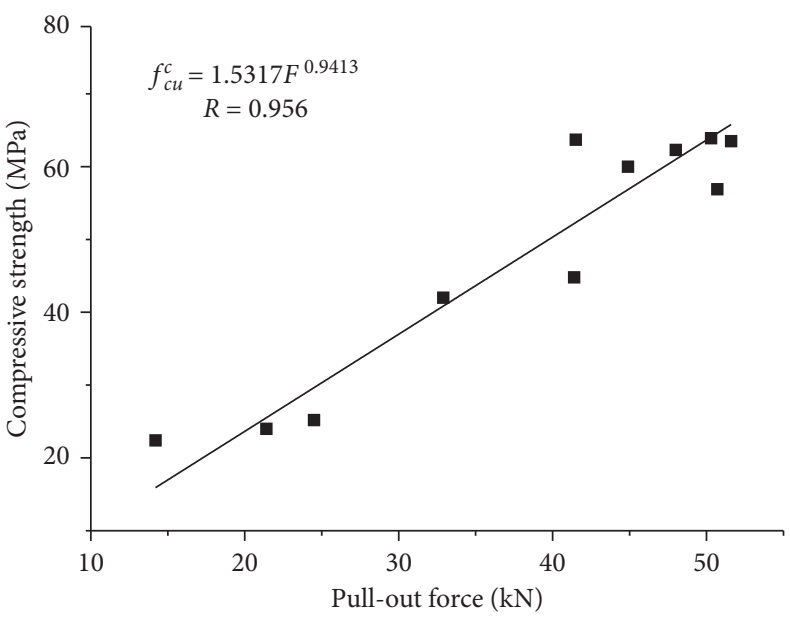

(b)

FiguRE 6: Relationship between the pull-out force and compressive strength obtained by the two different models in the postinstalled pullout test. Strength curves of (a) the Li model and (b) the Li et al. model.

because the material properties of steel fibers, carbon fibers, polypropylene fibers, and hybrid fibers are substantially different, and there is no effect of coarse aggregates on the steel fiber-reinforced mortar. As can be seen from $\mathrm{Ta}-$ ble $13, e_{r}$ of the model proposed herein $(4.85 \%, 4.25 \%$, and $3.99 \%)$ is significantly lower than that of the other two models $(5.43 \%$ and $5.97 \%)$. The $R$ value of the strength curves of PFRC, CFRC, and HFRC is approximately equal to 1 , indicating that the compressive strengths of PFRC, CFRC, and HFRC are strongly correlated with the pull-out force. In conclusion, there is a significant difference in accuracy and material characteristics between the strength curves currently available in the literature and the strength curves obtained in this study, and the strength curves of other researchers are not suitable for PFRC, CFRC, and HFRC. The results in this paper will provide a basis for establishing PFRC, CFRC, and HFRC compressive strength regression curves using the postinstalled pull-out method.

\section{Conclusions}

This study modelled strength curves using experimentally derived pull-out forces and $\mathrm{RN}$ values to provide a more accurate model for predicting the compressive strength of PFRC, CFRC, and HFRC. The following conclusions were drawn.

The regression functions for the compressive strengths of PFRC, CFRC, and HFRC obtained in the rebound hammer test were $f_{c u}^{c}=0.08324 R_{\mathrm{m}}^{1.72021} 10^{-0.02602 d_{\mathrm{m}}}, f_{c u}^{c}=0.15396$
$R_{\mathrm{m}}^{1.55588} 10^{-0.02147 d_{\mathrm{m}}}$, and $f_{c u}^{c}=0.14494 R_{\mathrm{m}}^{1.55466} 10^{-0.0178 d_{\mathrm{m}}}$, respectively. The relative errors between the predicted compressive strengths and the corresponding measured strengths in the rebound hammer test were low, in the range of $[0.053,0.058]$.

The regression functions for the compressive strengths of PFRC, CFRC, and HFRC obtained via the postinstalled pullout test were $f_{c u}^{c}=2.2535 F-3.821, \quad f_{c u}^{c}=2.1089$ $F-3.3377$, and $f_{c u}^{c}=2.1189 F-4.7076$, and the relative errors in the postinstalled pull-out test were in the range of [0.0307, 0.0406]. The developed regression equations demonstrated good correlations and precisions.

Compared with other models, the models proposed in this paper have better applicability and can accurately evaluate the compressive strength of FRC in the field.

\section{Data Availability}

The data used to support the findings of this study are available from the corresponding author upon request.

\section{Conflicts of Interest}

The authors declare no conflicts of interest.

\section{Acknowledgments}

The experimental tests were conducted in Shandong Provincial Key Laboratory of Civil Engineering Disaster 
Prevention and Mitigation at Shandong University of Science and Technology. The authors acknowledge the assistance from laboratory staff and students. The authors would like to thank Editage (http://www.editage.cn) for English language editing.

\section{References}

[1] K. Ali-Benyahia, Z.-M. Sbartaï, D. Breysse, S. Kenai, and M. Ghrici, "Analysis of the single and combined non-destructive test approaches for on-site concrete strength assessment: general statements based on a real case-study," Case Studies in Construction Materials, vol. 6, pp. 109-119, 2017.

[2] A. T. Moczko, N. J. Carino, and C. G. Petersen, "CAPO-test to estimate concrete strength in bridges," ACI Materials Journal, vol. 113 , no. 6 , pp. 827-836, 2016.

[3] H. B. Chen, S. K. Hu, and S. B. Feng, "Research on local curve of pull-out post-insert method for premixed concrete," Concrete, no. 2, pp. 114-116, 2012.

[4] E. Garcia-Taengua, J. R. Martí-Vargas, and P. Serna, "Bond of reinforcing bars to steel fiber reinforced concrete," Construction and Building Materials, vol. 105, pp. 275-284, 2016.

[5] J. F. Ye, H. Y. Chen, and X. S. Bi, "Experimental research of rebound detection in steel fiber concrete," Applied Mechanics and Materials, vol. 578-579, pp. 1108-1112, 2014.

[6] China Architecture \& Building Press, Technical Specification for Inspecting of Concrete Compressive Strength by Rebound Method, JGJ/T 23-2011, China Architecture \& Building Press, Beijing, China, 2011.

[7] B. S. Mohammed, N. J. Azmi, and M. Abdullahi, "Evaluation of rubbercrete based on ultrasonic pulse velocity and rebound hammer tests," Construction and Building Materials, vol. 25, no. 3, pp. 1388-1397, 2011.

[8] K. Szilágyi, A. Borosnyói, and I. Zsigovics, "Rebound surface hardness of concrete: introduction of an empirical constitutive model," Construction and Building Materials, vol. 25, no. 5, pp. 2480-2487, 2011.

[9] D. Breysse, "Nondestructive evaluation of concrete strength: an historical review and a new perspective by combining NDT methods," Construction and Building Materials, vol. 33, pp. 139-163, 2012.

[10] A. Jain, A. Kathuria, A. Kumar, Y. Verma, and K. Murari, "Combined use of non-destructive tests for assessment of strength of concrete in structure," Procedia Engineering, vol. 54, pp. 241-251, 2013.

[11] C. Chingălată, M. Budescu, R. Lupăsteanu, V. Lupăşteanu, and M. C. Scutaru, "Assessment of the concrete compressive strength using non-destructive methods," Bulletin of the Polytechnic Institute of Iasi-Construction \& ArchitectureSection, vol. 63, no. 67, pp. 43-56, 2017.

[12] K. Amini, K. Cetin, H. Ceylan, and P. Taylor, "Development of prediction models for mechanical properties and durability of concrete using combined nondestructive tests," Journal of Materials in Civil Engineering, vol. 31, no. 2, 2019.

[13] S. J. Li, "Experimental study on rebound method to test compressive strength of fiber reinforced recy-cled aggregate concrete," World Earthquake Engineering, vol. 31, no. 4, pp. 146-149, 2015.

[14] C. K. Mahapatra and S. V. Barai, "Sustainable self compacting hybrid fiber reinforced concrete using waste materials," Structural Concrete, vol. 20, no. 2, pp. 756-765, 2019.
[15] F. Laranjeira, A. Aguado, and C. Molins, "Predicting the pullout response of inclined straight steel fibers," Materials and Structures, vol. 43, no. 6, pp. 875-895, 2010.

[16] F. Laranjeira, C. Molins, and A. Aguado, "Predicting the pullout response of inclined hooked steel fibers," Cement and Concrete Research, vol. 40, no. 10, pp. 1471-1487, 2010.

[17] T. Abu-Lebdeh, S. Hamoush, W. Heard, and B. Zornig, "Effect of matrix strength on pullout behavior of steel fiber reinforced very-high strength concrete composites," Construction and Building Materials, vol. 25, no. 1, pp. 39-46, 2011.

[18] L. T. Bu, Q. Hou, and S. S. Chen, "Experimental evaluation of the strength of polypropylene-engineered cementitious composite in the post-installed pull-out method," Journal of Human University (Natural Sciences), vol. 40, no. 7, pp. 16-21, 2013.

[19] A. Lin and C. P. Ostertag, "Multi-scale pull-out resistance of steel reinforcing bar embedded in hybrid fiber reinforced concrete (HYFRC)," IOP Conference Series: Materials Science and Engineering, vol. 246, Article ID 012022, 2017.

[20] M. Roy, C. Hollmann, and K. Wille, "Influence of volume fraction and orientation of fibers on the pullout behavior of reinforcement bar embedded in ultra high performance concrete," Construction and Building Materials, vol. 146, pp. 582-593, 2017.

[21] D.-Y. Yoo and H.-O. Shin, "Bond performance of steel rebar embedded in 80-180 MPa ultra-high-strength concrete," Cement and Concrete Composites, vol. 93, pp. 206-217, 2018.

[22] China Planning Press, Technical Specification for Test of Concrete Strength by Pullout Method, CECS, China Planning Press, Beijing, China, 2011.

[23] L. T. Bu, J. Zhou, and Q. Hou, "Field testing the strength of thin-layer mortars using the pull-out method," Advances in Cement Research, vol. 28, no. 3, pp. 158-166, 2016.

[24] Y. T. Jia, Y. G. Yang, and J. Zhao, "Experimental study on the influence factors of rebound curve of modern concrete," Bulletin of the Chinese Ceramic Society, vol. 35, no. 6, pp. 1934-1939, 2016.

[25] China Architecture \& Building Press, Standard for Test Method of Mechanical Properties on Ordinary Concrete, GB/T 50081-2002, China Architecture \& Building Press, Beijing, China, 2003.

[26] H. Y. Liu, S. C. Zhao, and J. S. Wang, "Study on special strength curve of rebound method for concrete evaluation of oujiang river bridge," China Civil Engineering Journal, vol. 48, no. 1, pp. 41-48, 2015.

[27] K. Amini, M. Jalalpour, and N. Delatte, “Advancing concrete strength prediction using non-destructive testing: development and verification of a generalizable model," Construction and Building Materials, vol. 102, pp. 762-768, 2016.

[28] A. R. Khaloo and N. Kim, "Mechanical properties of normal to high-strength steel fiber-reinforced concrete," Cement, Concrete and Aggregates, vol. 18, no. 2, pp. 92-97, 1996.

[29] G. Zhao and J. X. Ma, "Detection of prepreg basalt fiber concrete strength with rebound method," Shanxi Architecture, vol. 37, no. 34, pp. 30-31, 2011.

[30] O. D. Atoyebi, O. P. Ayanrinde, and J. Oluwafemi, "Reliability comparison of schmidt rebound hammer as a non-destructive test with compressive strength tests for different concrete mix," Journal of Physics: Conference Series, vol. 1378, Article ID 032096, 2019.

[31] J. Su, Y. Chi, and K. Meng, "Experimental study of strength of steel-polypropylene hybrid fiber reinforced concrete subjected to true triaxial compression," Engineering Journal of Wuhan University, vol. 51, no. 1, pp. 40-46, 2018. 
[32] J. Y. Li, Experimental Research on Fiber Reinforced Cement Mortar Strength by Pull-Out Post-Insert Method, College of Civil Engineering Huan University, Changsha, China, 2010.

[33] Z. Q. Li, W. Bullock, J. Desai et al., "Non-destructive in-place concrete compressive strength estimation using post-installed concrete pullout test-methodology and field experience," in Proceedings of the Conference Structures Congress 2018, pp. 271-280, Fort Worth, TX, USA, April 2018. 